
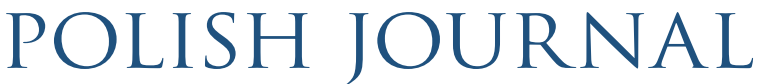

\title{
“Is my University White?" Exploring the role and influence of a University's Culture on the experiences of Black Undergraduate Students in the UK
}

\author{
Dorcas lyanuoluwa Fakile'
}

\begin{abstract}
This paper explores the long-standing attainment gap between Black male students relative to other student populations, within Higher Education Institutions in the United Kingdom. This paper attempts to develop a contextual understanding of the parallel relationship between the social and academic culture at universities in the UK, as well as identifies the barriers which affect Black male students' academic engagement. The purpose of this study is to answer the questions, "What is the Black male student experience at one university in the UK?" and "Which attitudes and practices at this university promote diversity and inclusivity and which hinder this?" The research was conducted via interview to gain a better understanding and acknowledgement of the multiple truths grounding this subject matter (Jones, 2015). The main participants were four Black male undergraduate home students, and four White academic staff members, at a University in the United Kingdom. This paper concludes by recognising that the meanings and attitudes attached to the attainment gap vary significantly. The key recommendations identified were the importance of raising Black representation within the staff, as well as developing a racially conscious atmosphere, in order to develop a sense of inclusion and belonging within the Black male student population.
\end{abstract}

\section{KEYWORDS:}

Black students, attainment gap, critical race theory, student experience

1 University of Northampton, United Kingdom E-MAIL: dfakile@gmail.com ORCID: 0000-0001-6215-6092 


\section{Introduction}

This paper comes from a study into the attainment gap between Black students and their White counterparts at one university in the United Kingdom. It analyses the reasons for this gap that are attributed to it by students and staff.

An attainment gap refers to any significant and persisting disparity in academic attainment, between different groups of students. As regards this study this particularly relates to the attainment of 'top degrees' specifically the difference in the percentage of White students achieving a first or upper second class (2:1) degree, compared to the percentage of Black students achieving these.

This matter has come under considerable scrutiny within recent years, with gender and ethnicity predominantly identified as the key factors (Cotton et al. 2015). Explanations regarding this matter, have often explained this, in terms of the 'deficiencies' of students (Smith, 2017). This places a specific focus on the individual's socioeconomic status and family structure. However, such perspectives effectively deflect the blame and responsibility from the institution, onto the individual. Approaches towards understanding this attainment gap often focus specifically on the impact of the formal curriculum. And exclude the influence of the 'hidden' curriculum, which in this context refers to the unspoken and implicit values and norms that exist within the educational social culture (Koppie, 2017). This effectively limits our understanding and creates a false impression of the causes of the attainment gap. Therefore, there needs to be a shift towards research that analyses the impact of the 'whole' university culture and that takes into consideration the broader student experience at Higher Education Institutions. The whole university culture within the context of this research is defined as encompassing student-teacher relationships, the existence and acceptance of student associations and the forms of social engagement supported by the university (Koppie, 2017).

This approach enables the development of a thorough understanding of the underlying messages being taught in a student's daily encounters. Thus, this research attempts to develop a contextual understanding of the Black male student experience at one university in the UK, as well as, identifying the barriers which affect their academic engagement. This is done through the voices of students and academic staff members at the case study university.

The following research questions are answered in this paper:

1. What role and influence does the university culture have on black male students' experiences at one university in the UK?

2. What attitudes and practices at this university promote diversity and inclusivity and which hinder this? 


\section{Conceptual Framework}

The conceptual framework of this research is underpinned by elements of critical race theory. Critical race theory is a thematic approach that fundamentally perceives race as the prism through which its proponents analyse all aspects of society (Sawchuk, 2021). This effectively views educational institutions as places where processes are shaped by the interests of the dominant White population (Gillborn, 2014).

Furthermore, critical race theory (CRT) frames race as a social construct, and racism as its by-product (Sawchuk, 2021). This recognises racism as a normal feature of society, as it is embedded within its systems and institutions (George, 2021). This section explores these ideas in relation to the Black attainment gap.

\section{The intersection of Race and Gender}

The issue of race and ethnic inequality in Higher Education Institutions has been a significant concern for over a decade. The Higher Education Statistics Agency (HESA) first revealed a disparity in attainment, in the late 1990s (Senior, 2012). Although, it was not until 2003, that academics began to research this area in depth. Almost 20 years ago Connor et al. (2003) concluded that several specific ethnic minority groups were less than half as likely to obtain a good degree. This stimulated other scholars to produce comparable research and analysis, which largely agrees with such a statement and explains that the causes of the attainment gap are complex and multifaceted (Stevenson, 2012; Smith, 2017; Austen et al., 2017; Ross et al., 2018).

The 'Equality in Higher Education Report' 2020 (AdvancedHE, 2020) revealed that $81.4 \%$ of White students achieved a first/2:1 degree; whilst $68.0 \%$ of Black and ethnic minority students (BME) achieved this same degree classification. This shows an overall gap of $13.3 \%$, revealing that the largest attainment gap within Higher Education Institutions remains between BME students and their White counterparts. However, further to this, this report revealed that Black students are the lowest-performing group; with a 22.6\% gap (AdvancedHE, 2020) from their White peers. Despite this attainment discrepancy, research has often paid too little attention to attainment differences between each ethnic group - too often it has joined the different ethnic groups together, to highlight the gap between White and BME students (McDuff et al., 2018). This consequently has over-simplified the complexity and influence ethnicity has on the issue of attainment (Stevenson \& Whelan, 2013) therefore, resulting in distortion of our understanding of the subject matter.

Furthermore, it is assumed that because there has been a continuous increase in Black students at UK universities that these universities have become inclusive and have adopted a culturally diverse curriculum. The Equality, Diversity, and Inclusion (EDI) policies of Higher Education Institutions have often encouraged this mentality. 
As such policies and statements have acted as a checklist of pointers for actions taken towards the issue of racial inequities (McDuff, 2018). Thus, enforcing the notion that putting strategic plans in place for each pointer; can fix everything about equality and equity within these institutions (Tate, 2019).

Such a perspective relates to the theory of interest convergence within critical race theory, which proposes that diversity and inclusive practices can often be implemented for the best interests of those in power, and not necessarily due to 'moral persuasion' (Delgado \& Stefancic, 2001). This attitude can lead to effectively underestimating the consequences of race in universities, therefore, encouraging educational institutions to remain in a state of denial regarding their diversity and inclusive practices (Smith 2017), whilst the experience of Black students may be far from positive.

One significant result of the Black attainment gap is the limiting of future educational and employment opportunities for Black students, post-graduation. This is because many graduate-level jobs and post-graduate courses require a minimum entry requirement of 2:1 or above (Randall et al., 2021). However, the attainment gap reveals that more Black students attain a lower degree classification of 2:2 or third (HESA, 2021). This means that Black graduates are less likely to benefit from these opportunities (AdvancedHE, 2019). Additionally, research has shown that the overall quality of life for Black men demonstrates the impact of this educational disparity - statistically Black men are least likely to be hired, first to be laid off and experience vast income inequalities compared to their white male counterparts (Allen, 2015). Even within the Black community there are further subtle distinctions - Black Caribbean students are typically third generation UK born, while many Black African students are more recent immigrants. It is suggested that minorities who have been long established in a country, particularly in a context of racial and socio-economic disadvantage may be the least likely to be optimistic about the possibilities of social mobility and education to transform their lives (Commission on Race and Ethnic Disparity, 2021).

The Equality in higher education survey (Advanced HE, 2020) also revealed a gender disparity of 5.1\%: within the black student population, with male students achieving less than their female counterparts. Sociological research has often explained this difference through social constructs of gender/sexual power relations, and through the concept of 'hegemonic masculinity'. According to definitions of hegemonic masculinity, academic work is often perceived as 'feminine' (Frosh et al., 2003), therefore, male students avoid academic work in order to reject being labelled as feminine (Jackson, 2003). Holloway (2016) also explains that the wider perception of Black male 'underperformance' in their university studies is influenced by stereotypical ideas around Black masculinity. 


\section{The Deficit Model}

The deficit perspective model situates the causes for the attainment gap as being a sociocultural issue, and due to faults within an individual that have accrued through past environments, rather than due to faults within their current situated learning environment (Silverman, 2011). This places a specific focus on the internal (cognitive or motivational) and external (cultural, family, or socioeconomic background) factors of Black students. This account emphasises, that Black communities in the UK, have a long history of struggle against racialised oppression and face multiple forms of institutional discrimination (Christian, 2005) and that this inevitably feeds indirectly into the treatment of Black children in the educational system. However, when such historical disadvantages are used to explain the attainment gap, the result is that it is still frequently attributed to a lack of personal effort or deficiency, in the students (Volk \& Long, 2005). Furthermore, there is a risk that this mindset can perpetuate stereotypes and effectively alienate students from the university's culture (Smit, 2012), whilst the university can explain away the attainment gap on the basis of past experiences rather than the current learning environment.

\section{Institutional Racism}

The term 'institutional racism' dates back to 1967, it was first used by Black activists - Stokely Carmichael and Charles V. Hamilton. This term was generated as a way to distinguish the difference between individuals who held racist attitudes and the much larger existence of racial biases that are expressed within an organisation (Miller 2016). Simply put, institutional racism refers to racial discrimination that has become established as the norm within an organisation as a result of the collective beliefs and actions of the population. The implication of this is that while this is the product of a group of individuals in an organisation, who each hold racist attitudes, this has resulted in the production of uncritically maintained organisational structures, policies, and procedures, which largely benefit the White population (Miller, 2016). Furthermore, Bhopal (2020) argues that universities are institutionally complacent in reproducing the status quo, which is White dominated. Therefore, the issue of race inequality within universities has become a permanent feature of the United Kingdom's educational system, and replicates the rigid social stratification of society (Gillborn, 2008), even when contemporary barriers to equality are removed, discrimination remains (Phillips, 2011).

\section{Inclusion and Belonging}

Whilst the increase in the Black student population has proven to be economically beneficial for UK universities, Sleeter and Grant (2008) have noted that this has had little impact on their educational ethos, teaching practices and curriculum. There- 
fore, although universities may appear to be visually diverse, in truth, the integration of diversity is very dysfunctional.

Diversity is often described as understanding that each individual is unique and recognizing individual differences. This implies that there is a need to develop a sense of cultural intelligence in order to cultivate a diverse community that is functional. Nevertheless, whilst the need for incorporating participation, belonging, attainment and retention, is highly recognised across these institutions, it is clear that little has been done to develop inclusive practices that embrace and celebrate diversity.

In 2011 the National Union of Students 'Race for Equality' survey (Miller, 2016) revealed that Black students are less likely to be engaged with their educational experiences. This is due to factors such as feeling isolated, unwanted and excluded from their institutional environment. In relation to this, a focus group study conducted at Kingston University demonstrated that more than $80 \%$ of Black and ethnic minority students did not feel as if they were part of their university community (Miller, 2016). In comparison to this, $72 \%$ of their White counterparts perceived themselves otherwise (Miller, 2016). This may have been caused by academics failing to fully adjust their teaching practices to support and engage with the diversity of students or other issues with the students' current learning environment (Durden et al., 2014), leaving most students feeling excluded and unmotivated with their educational journey. (Richardson 2008).

\section{Representation}

The proportion of Black or ethnic minority staff in universities in the UK is markedly lower than the proportion of White staff. Only $10.3 \%$ of higher education staff identify as Black or from an ethnic minority (AdvancedHE 2020). This representation, therefore, does not correlate with the higher representation of students from the same demographic. This severe disparity of ethnic representation may result in students' disengagement and lack of aspiration in their educational journey (Arday, 2018). Moreover, there is also a lack of representation within students' formal curriculum. The University College London 'Why is My Curriculum White?' movement highlights the dominance of a White culture and a Eurocentric curriculum in universities, which Black students are unable to relate to (Elliott-Cooper \& Bouattia, 2015). This is further emphasized in case study research conducted by the National Union of Students (2018), which reflected on the impact of a lack of representation in the formal curriculum. The report highlights that $42 \%$ of Black students did not believe that their curriculum reflected issues of diversity, equality and discrimination. Moreover, $34 \%$ stated that they felt unable to bring their perspective as a Black student to their lectures. The student comments focused on the concept of a 'mainstream' way of thinking which therefore excludes students from diverse backgrounds (NUS, 2018). 


\section{Method}

This research aims to develop an understanding of the social phenomena of Black male students' experiences, within their university through the voices of the students and academic staff who work there. An interpretive method was adopted, in order to gain a better understanding and acknowledgement of the multiple truths within the subject matter (Jones \& Gratton, 2015). This draws on the participants' range of voices and personalities, through a narrative structure, recognising that individuals understand reality in different ways. The use of qualitative data, therefore, focuses on examining the thoughts and practices that contribute to these real-life perspectives, in order to understand complex situations in their natural settings. This paper is a small-scale case study. The main participants were four Black male undergraduate home students and four academic staff members, at a University in England that is not affiliated to the author.

\section{Data Collection (interview)}

A semi-structured interview approach was used for the data collection, to allow more flexibility regarding the flow and direction of the interviews. This also enabled the development of new and deeper perspectives, from the participants' point of view.

Although we had written a list of set questions prior to the interviews; this was to help stimulate responses from the participants. The interviews were not fully reliant on these questions, and often we used the new knowledge shared from the participants' experiences to generate further questioning. The student interviews all took place on different days, in a social setting (selected by each participant) at the university, with one exception which took place online through video call. The staff interviews took place in an office space at the university on the same day.

Four Black male undergraduate home students (from different year groups) were selected as the first sample group.

Student 1: $\quad$ Black Caribbean, 21

Student 2: $\quad$ Black African 21

Student 3: $\quad$ Black Caribbean 19

Student 4: Black African 20

We chose these specific students, due to their affiliation with the student union, as each participant was an active committee member of a club/society within the student union, as well as a staff member of the student union full time officers. This commit- 
ment to the university community led us to believe that they would be able to provide a comprehensive account of their experience at the university.

To gather a deeper insight into the issues regarding the subject matter, a second sample group of four academic White staff members was included in the research. Each staff member was contacted through a pre-existing relationship with the authors, in which each had demonstrated an interest in issues of education inequality. Quotations from each of these groups of participants have been included in the findings, with the data presented thematically.

The data analysis process of this research was completed in a sequence of steps (Jones, 2015). In addition to recording the interviews, each of the interviews was transcribed verbatim and later organised into Braun and Clarke's (2006) 6-step thematic analysis framework. This involved examining all the raw data collected, then reducing and organising them into a colour coordinated format. That was later formatted into a thematic diagram according to emerging themes. These themes then informed the presentation of the data in the sections below.

\section{Findings and Discussions}

The ways in which the participants (particularly the student participants) depicted the Black attainment gap were highly complex. Generally, there was a lack of awareness of what the Black attainment gap was, among the students. This meant that they had not previously correlated the attainment gap as a racial issue, although they perceived that their Black peers often struggled to be successful in their academic studies. Similarly, the staff members all acknowledged the Black attainment gap to be problematic and agreed that the Black student experience can be more challenging, compared to their White counterparts. Thus, this section analyses and discusses implications of the dialogues shared during the research process.

\section{The Deficit Perspective}

\section{Student's Attitude}

Most of the students' responses on the attainment gap, attributed it to aspects of character and behaviour and therefore, involved an element of 'self-blame'. It was implied by the participants that the reasons Black students attain a lower degree was due to internal and uncontrollable factors such as their cultural and socioeconomic capital as well as other controllable habits such as their engagement with their learning process. 
According to the students who were interviewed, those with lower attainment outcomes often approach their educational journey, with the wrong attitude. Such students were described as executing their first year with an "I just need a pass mentality" partnered with a "partying" lifestyle. According to these participants, this then effectively resulted in students becoming neglectful and uninterested in learning.

"The whole thing about you only need $40 \%$ or $50 \%$ to pass the first year, that got into a lot of our heads because it's like you can just spend your first-year partying all along, and you don't have to worry about what you're actually in it for. So that was the illusion that we come here with." (Student 4)

According to the students who were interviewed, such a mindset negatively influences students' choices and becomes a means of distraction. Additionally, if such a lifestyle is being inculcated from the early stages of their academic journey, this would set the standard for the rest of their academic years, therefore initiating students into a negative habitual lifestyle. In response to why this predominantly affected Black students, the student participants heavily criticised the clubs and societies that are specifically directed to the Black demographic, such as the African, Caribbean Society (ACS). They stated that such societies mainly promote and portray a partying lifestyle to students. Although arguably such events create a networking opportunity for students from similar backgrounds to connect with each other. Which in turn can promote the sense of belonging for such students within the university's culture.

"I would say the ACS or...just our demographic itself kind of persuade us to indulge in a lot of activities... which isn't bad...you can choose whether you want to do it or not. But the fact that there's a lot of parties every other week, some people always go there. Because there's always something to do...that can be a distraction." (Student 4)

This perhaps seems an inadequate explanation as there are similar socially focused clubs and societies for all demographic groups at the university. Other writers in this field have challenged the validity of this self-explanation and indeed the culture of self-blame within Black communities in comparable studies to this one (Smit, 2012). However, the purpose of this specific article is to present students' authentic voices, and this is an accurate reflection of these students' perceptions.

\section{Socio-economic Background}

Further to the discussion on why attainment disparity predominantly affects Black students - one of the staff members highlighted the impact of the students' socioeconomic status. This was described as having a critical effect on students' engagement with their academic practice. 
"The Black population tends to come from lower socioeconomic groups. So perhaps more of them work - which puts the pressure more on them. They aren't really just full-time students. A lot of Black students I've worked with are full-time student, part-time worker actually and that might have an impact." (Staff 2)

This viewpoint helps us to understand the problem of finding time for studying for students who are financially unstable. Students with a poor socioeconomic status are forced to become part-time workers even if they are full-time students, and as such their time is often split between work and studying.

\title{
First-generation Students (FGS)
}

A few of the students highlighted how being a first-generation student (FGS) put them in a disadvantageous position from the start in comparison to their peers.

\begin{abstract}
"The other race - they look at themselves as a collective and they always have a certain level of knowledge they come up from anyways. Whether that be their parents or their heritage. A lot of Africans or Caribbean people...they don't often have parents who already went to university. Parents that are of intellect...I'm not saying that they're stupid or anything, but they didn't grow up having that sort of foundation of knowledge...not a lot of Black males have that." (Student 2)
\end{abstract}

The students' explanation of the challenges that they face matched with this experience - as defined in other research. First-generation students are generally defined as those students where neither parent had access to higher education (Thomas \& Quinn, 2007). These students' university experiences typically prove to be more challenging, as opposed to continuing-generation students (CGS). Because they have to navigate their way through their new environment, with limited social and cultural capital (Beattie, 2018). Furthermore, this issue was also explored by one of the participating staff, who explained that:

"If you come to University and you're the very first person to ever go to university you're working at an academic level beyond your parents and your family. So, you haven't got that kind of knowledge to dig into." (Staff 1)

This lack of (or limited) knowledge and expectations, has been described as contributing to differences in student's preparedness, retention and attainment (Atherton, 2014). The transition from sixth form or college to university was identified by the student participants as "already a big enough hurdle for all students". However, they perceived this as even greater for first-generation students. The student participants expressed that in school, the teachers "will teach you EVERYTHING, and give you all the answers". They went on to describe how they are used to getting help and gaining all their information from the teacher. However, when they arrive at university, they 
often struggle to be completely independent in undertaking their own research, and in going beyond what is being given to them, to get the grades they desire. Therefore, without the extended knowledge and support from family, first generation students often have to navigate their way through such changes on their own.

"... when you get to uni, it's not the same as high school. $95 \%$ of the work is you, and $5 \%$ is the lecturer. But some of the students are making it like 50/50. University is all about you going home to find those 95\%, by doing research....They're going to teach you what you need to know, then you're going to go home and find out what else you also need and want to know that can help you, to get your grade." (Student 3)

Further to this, the students described how they felt that the social and academic transitional challenges that first-generation students face are often neglected by the university. They perceived that the drastic change in the academic structure that they are working within, effectively causes students to easily become disengaged with their module content, especially if they have no additional support from staff from their cultural background.

Whilst the participants described how the case study university somewhat attempts to support this transition, through various pastoral activities, such as 'the welcome week', to help students adjust to their new environment - it seemed to them as if such practices disintegrate throughout the year, therefore, leaving them to their own devices to properly adjust to the university culture. Thus, students were constantly left feeling "uneasy" within the case university's setting. The students described how this disoriented their experiences and resulted in them becoming frustrated and isolated from their environment.

\section{Beyond the Deficit}

On another note, the deficit explanation, even when it attributes problems to long term societal factors, was seen by the participants as too often resulting in Black students being perceived as being inferior to their White counterparts. The deficit model was specifically described as limited by one of the students who highlighted that more significant problems are to do with time and student-lecturer interactions. This participant felt that students are simply too often left to their own devices with very limited support from their lecturers. Yet, they are automatically blamed and faulted when they fail to meet the academic standards set out. In addition to this, the deficit model was depicted as a "lazy argument", by one of the staff members, who expressed that such argument places too much focus on decontextualizing the characteristics of an individual (Weiner, 2016), to justify the root of the societal issue, effectively blaming the victim, rather than examining the hegemonic nature of the micro-society (the university) they are currently functioning within. 
The majority of the interviewees disregarded the influence of race and ethnicity on attainment. Instead, they expressed a belief that all students regardless of their ethnicity struggle with adjusting and engaging with the university's culture. Both participating groups referred to the attainment gap mainly as a "universal issue, which creates problems and barriers to participation and engagement", for all students. In the exploration of this idea, three key notions were identified as contributing factors to student's engagement; the attitude of staff; learning, teaching and assessment practice; and the university culture.

\section{The Attitudes of Staff}

Across all the staff interviews, there was evidence of a strong commitment to widening participation and developing inclusive practices to ensure equality across the institution. However, it was clear that there was a reluctance amongst academic staff members to address the Black attainment gap, within their particular field out of fear of being blamed. One of the lecturers described one situation that they had encountered as follows:

"I spoke to a colleague, about it... I said, you know, I found this out. He said oh that's a big difference, and I said yeah, I'm gonna have to go and talk to someone about it. And he said don't. whatever you do, don't mention it...you'll be to blame. As soon as management finds out, it'll be you, because it's your module." (Staff 3)

This culture according to this lecturer inhibits the structural changes required for the case institution to properly address its racial division and tensions. Because staff are nervous about being judged, those conversations which would begin to enable change are not possible. This, therefore, illustrates the structural nature of racism within universities, where the culture of blame means that staff cannot create change in their own or others' attitudes and practices. This statement also showcases the misconceptions associated with the idea of race and racism. It was also described that oftentimes in discussions about racism and Whiteness, individuals quickly become defensive and reserved, to avoid being labelled as racist. However, this lecturer saw it as imperative to emphasise that these discussions do not seek to label people as such. Having open, meaningful and constructive conversations about ethnicity, race and racism to this participant are vital in addressing the issues of racial inequalities at universities. They are therefore needed to increase awareness and move towards removing the racial tensions that have been embedded within the institution's environment. Constructive dialogue on race has to be enabled as a means of healing the racial and ethnic divide and increasing racial literacy within the institution (Sue, 2013). 


\section{Learning, teaching and assessment practices (LTA)}

The students' responses to the learning, teaching and assessment practices at the university varied significantly. Whilst the student participants felt somewhat supported in their academic studies, they also felt that some practices hindered their academic abilities. Such practices included poor personal tutoring sessions, lack of general support and inadequate feedback. The interviewed students however also expressed that all ethnic groups are negatively impacted by poor learning, teaching and assessment practices.

"I do feel like it was a case of they'll point out that you're not good at it, but it was never a case of...okay, this is how you should set out. Because I guess there's an understanding of, you're in university, you should know how to do it. There was never a 'we're going to sit through and say what you need to put in'..." (Student 2)

Whilst the concern to assist students in their personal and academic development in higher education is an integral element in the educational sector. The extent to which lecturers should help students is often debated. This is because the university culture is disinclined to support students over-actively throughout their academic journey (Thomas, 2012). Rather, it directs students away from being too reliant on academic staff, in order to become independent learners. As the staff participants pointed out - the aim of this is to encourage students to become specialists in their field. Nevertheless, the role of academic staff was seen by the students as being significant to students' engagement with their module content.

"It is more than lifestyle as well, it's about the module content. It goes from lecturer to lecturer as well. If you get a good lecturer that cares, I think you'll work harder in class, you'll probably turn up to class more as well, if you like the lecturer, and if the lecturer goes beyond as well." (Student 1)

Under this impression, some of the students stated that they specifically chose to not attend their academic tutorial session, because they felt that such sessions were unhelpful due to the lecturers' failure to keep the students motivated and valued. Mostly, there was a perceived "lack of support" from lecturers, as they failed to build a relationship with their students. The students stated that often, when they asked for help, the lecturers did the "bare minimum", by constantly referring them to the module guide and leaving them to their own devices.

On another note, mental health was identified as a key issue during the students' interviews. It was expressed that whilst there are support systems in place to help students struggling, those practices are not effective enough to help students when necessary. 
"Mental health is a big issue, at this university. I think if you go to the mental health facility and you want to book an appointment, I had a wait of like 4 months or something like that. So, if you're struggling, that's it basically, there's no help...what could happen in four months really..." (Student 1)

Levels of mental illness among students in Higher Education Institutions in the UK are rapidly on the rise. A recent study revealed that 1 in 5 students suffer from a mental health issue, with depression and anxiety listed as the leading diagnoses (Pereira et al., 2019). Arguably, the implications of such mental health problems contribute to poorer academic outcomes as students are unable to effectively manage stress and pressures, which diminishes their level of productivity (Yap, 2018). Moreover, it is argued tha the effects of racial hostility within the university's culture has a notable impact on Black students' mental health (Anderson, 2020). Despite this, Black male students are significantly less likely to seek help with mental health issues (Hankerson et al., 2015).

\section{University Culture and Approach to Racism}

The case university was heavily criticised by the participants for its unsympathetic approach towards addressing the Black attainment gap. The participants instead perceived a university culture that mainly reflects a "traditional White middle to upper class" population; to which Black students are unable to relate. Therefore, it is clear that according to this perspective that universities still have a long way to go in dismantling the racial inequalities in their whole curriculum. Noticeably it was not only the students who perceived this. In support of this, one of the academic staff commented that:

"I think the universities were very dominated by White academics. You know, I mean still, there is a challenge that lectureships are dominated. We have at this University; we have a large Black British population. But if you look at the lecturers and stuff, it's so predominantly White. And writing is still dominantly White, and it's dominated by White writers and if you're looking back on these seminal writers through the 50s into the 80s, then it's absolutely dominated by White men because universities were dominated by White men." (Staff 1)

Despite the strong evidence of multiculturalism within the university's settings, most of the students expressed a sense of exclusion from the university's culture due to dominant White cultural norms. They stated that the university's curriculum reflects a 'colour-blind' approach (Neville et al., 2013) which operates as a bandage to cover up the problem, instead of addressing it. Therefore, preventing the institution from recognising the historical influences of institutionalised racial inequality. Thus, essentially helping to maintain the misperception that Whiteness is normative and that Black students are lesser. The participants also felt that the university tended to avoid the discussion of racial issues, which contributed further to racial tension within the university and left racial issues, such as the Black attainment gap, unresolved. 
Regarding this, the students described the university as "institutionally racist". This was based on the university's approach towards specific incidents and Black students. It was discussed that the university portrays Black students as "guilty by association", in all incidents. Whilst being more lenient towards White students under the same circumstances. One of the students explained a specific incident, which revealed to them the racial bias within the university.

"There was the 'take me out' event in town. Based on the TV show Take Me Out, some of the Black students organised an event around it. And then afterwards there was a fight, and the police turned up. It was this huge bull in town, and it was hectic...I heard about it afterwards from ACS. It wasn't their event, but they got blamed for it by the university, just because they happened to be a Black society at the university. So, you just assume it was their event.... just guilty by association." (Student 1)

This example reveals how the university approaches issues relating to Black students through a negative stereotypical lens, often acting irrationally specifically towards Black students.

"Because of the biases against Black people, like how the media operates. They've linked Black to crime. Like being Black has been criminalized and subconsciously society begins to think like that." (Student 1).

Additionally, the students also drew attention to racial tension within their formal curriculum. They explained that they did not feel confident enough to write honestly about their thoughts and experiences on race in their essays. They felt that most of the time, they had to "filter" their speech, "out of fear of offending White people".

"I did creative writing, and we had English modules, and a lot of them were like 200 years old, 300 years old sometimes. And the stories are racist as well. Yet, you have to write essays on these stories objectively. How can you write (when you're Black or Asian) about racism without some form of emotional attachment to it?" (Student 1)

Moreover, when racial discussions are brought up, within their module context, the students expressed that the discussions held surrounding this are often portrayed through a White lens which includes elements of implicit bias. However, it is important to note that they also reflected on the challenges posed by Black students having an "emotional attachment" to racial issues. As it reflects their lived-out experiences. Therefore, when it is portrayed from the White perspective, such discussions appear to be insensitive towards Black students.

The participants also identified tensions and challenges with creating space for dialogue. Both of the participating groups described the university's approach to racial discussions to be problematic. It was explained that often when opportunities opened up to address racial tensions and the Black attainment gap the spaces were 
mainly filled with Black students. Thus, it appears as if the responsibility is placed on them to find the solution for the racial issues.

"I feel like White people think that they're not allowed to talk about race, because they're White. They can, everyone is a person, everyone exists, and everyone has a right to an opinion, but if they say something wrong, I'll tell them. I'll discuss it with them, I'm not going to vilify them for getting it wrong." (Student 1)

The implication of this is that their White peers were left in a state of ignorance regarding the matter of race. However, it is important to note that to these participants the issue of racism is not Black people's responsibility to solve as they did not create the problem. And it is unfair to essentially place such responsibility on the 'victim' of the issue.

\section{Conclusions}

If the case of this university is treated as typical and if these student and staff voices are understood as meaningful and us eful, it is clear that UK universities still have a long way to go in addressing the Black attainment gap and its causes. In this exploration of Black students' experiences at one university; the whole student experience was seen as significant. There is no simple explanation for the attainment gap. The meanings and attitudes attached to it varied significantly across all participants. However, significant commonalities emerged. Firstly, it was noticeable that most of the Black male students lacked awareness of the attainment gap especially since they are the most affected group. Secondly, staff and student participants identified significant barriers to enabling dialogue and facilitating structural change.

The following are key recommendations that the students and staff made. These are presented without judgment in the spirit of this paper, which is to present the authentic voice of these students and staff. These recommendations may be open to challenge from a pedagogical or pragmatic perspective. However, they present a snapshot of current views at a single case study university, which may be more widely applicable to other universities in the UK. The recommendations are:

1. The importance of developing a racially conscious atmosphere within the context of the institution, to develop an awareness of the attainment gap, specifically to:

- create more safe spaces for racial discussions (inclusive to everyone).

- remove the stigma and blame culture of racism, by educating staff and students on the definition of racism. 
2. The importance of raising Black representation within the staff body, and within university culture; to develop a sense of inclusion and belonging. That is not limited to a single 'Black and Ethnic Minority' officer. This was identified as a good start, but it is important to note that it was seen as not the sole responsibility of the Black representative to address the issues of inclusion.

3. The need for developing a parallel relationship with academic staff and members of the student union to effectively cater for the needs of all students.

\section{References}

Advanced, H.E. (2020). Degree attainment gaps. Advance-he.ac.uk. Retrieved 13 February 2021. https://www.advance-he.ac.uk/guidance/equality-diversity-and-inclusion/student-recruitment-retention-and-attainment/degree-attainment-gaps\#ethnicity

Advanced, H.E. (2020). Staff statistical report 2020 (pp. 130-197). AdvancedHE. Retrieved from https://www.advance-he.ac.uk/knowledge-hub/equality-higher-educationstatistical-report-2020

Advanced, H.E. (2020). Students statistical report 2020 (pp. 126-197). AdvancedHE. https:// www.advance-he.ac.uk/knowledge-hub/equality-higher-education-statisticalreport-2020

Akkerman, S., \& Van Eijck, M. (2013). Re-theorising the student dialogically across and between boundaries of multiple communities. British Educational Research Journal, 39, 60-72. https://doi.org/10.1080/01411926.2011.613454

Allen, Q. (2015). "I'm Trying to Get My A": Black Male Achievers Talk About Race, School and Achievement. The Urban Review, 47(1), 209-231. https://doi.org/10.1007/s11256-0140315-4

Arday, J. (2018). Understanding race and educational leadership in higher education. Management In Education, 32(4), 192-200. https://doi.org/10.1177/0892020618791002

Atherton, M. (2014). Academic Preparedness of First-Generation College Students: Different Perspectives. Journal Of College Student Development, 55(8), 824-829. https://doi. org/10.1353/csd.2014.0081

Austen, L., Heaton, C., Jones-Devitt, S., \& Pickering, N. (2017). Why is the BME attainment gap such a wicked problem?. The Journal Of Educational Innovation, Partnership And Change, 3(1), 147. https://doi.org/10.21100/jeipc.v3i1.587

Beattie, I. (2018). Sociological Perspectives on First-Generation College Students. Handbook Of Sociology Of Education In The $21^{\text {st }}$ Century, 171-191. https://doi.org/10.1007/978-3319-76694-2_8

Bhopal, K. (2020). Race, white privilege and business as usual [Blog]. Retrieved 6 July 2021. https://www.hepi.ac.uk/2020/07/21/race-white-privilege-and-business-as-usual/

Braun, V., \& Clarke, V. (2006). Using thematic analysis in psychology. Qualitative Research In Psychology, 3(2), 77-101. https://doi.org/10.1191/1478088706qp063oa 
Butcher, J., \& Gonzalez, M. (2021). Critical Race Theory, the New Intolerance, and Its Grip on America. The Heritage Foundation. https://www.heritage.org/sites/default/files/202012/BG3567.pdf

Christian, M. (2005). The Politics of Black Presence in Britain and Black Male Exclusion in the British Education System. Journal Of Black Studies, 35(3), 327-346. https://doi. org/10.1177/0021934704268397

Commission on Race and Ethnic Disparity. (2021). Commission on Race and Ethnic Disparities: The Report. https://assets.publishing.service.gov.uk/government/uploads/system/uploads/attachment_data/file/974507/20210331_-_CRED_Report_-_FINAL__Web_Accessible.pdf

Connor, H., Tyres, C., Davis, S., \& Tackey, N. (2003). Minority Ethnic Students in Higher Education: interim report. Department for Education and Skills. http://mailserver1.ligali. org/pdf/minority_ethnic_students_in_higher_education_rr448.pdf

Cushman, K. (2007). Facing The Culture Shock Of College. Educational Leadership: The Prepared Graduate, 64(7), 44-47. Retrieved 13 February 2021. http://www.ascd.org/ascd/ pdf/journals/ed_lead/el200704_cushman.pdf

Durden, T., Dooley, C., \& Truscott, D. (2014). Racestillmatters: preparing culturally relevant teachers. Race Ethnicity And Education, 19(5), 1003-1024. https://doi.org/10.1080/1361 3324.2014.969226

Frosh, S., Phoenix, A., \& Pattman, R. (2003). Taking a stand: Using psychoanalysis to explore the positioning of subjects in discourse. British Journal Of Social Psychology, 42(1), 39-53. https://doi.org/10.1348/014466603763276117

George, J. (2021). A Lesson on Critical Race Theory. Americanbar.org. Retrieved 2 July 2021. https://www.americanbar.org/groups/crsj/publications/human_rights_magazine_ home/civil-rights-reimagining-policing/a-lesson-on-critical-race-theory/

Gillborn, D. (2008). Coincidence or conspiracy? Whiteness, policy and the persistence of the Black/White achievement gap.Educational Review, 60(3), 229-248. https://doi. org/10.1080/00131910802195745

Gillborn, D. (2014). Racism as Policy: A Critical Race Analysis of Education Reforms in the United States and England. The Educational Forum, 78(1), 26-41. https://doi.org/10.10 80/00131725.2014.850982

Holloway, L. (2016). How black young men are overcoming the label of educational 'failure' to achieve success. Runnymedetrust.org. Retrieved 7 July 2021. https://www.runnymedetrust.org/blog/how-black-young-men-are-overcoming-the-label-of-educationsfailure-to-achieve-success

Jackson, C. (2003). Motives for 'Laddishness' at School: Fear of failure and fear of the 'feminine'. British Educational Research Journal, 29(4), 583-598. https://doi.org/10.108 0/01411920301847

Janoff-Bulman, R. (1979). Characterological versus behavioral self-blame: Inquiries into depression and rape. Journal Of Personality And Social Psychology, 37(10), 1798-1809. https://doi.org/10.1037/0022-3514.37.10.1798 
Jenkins, K. (2018). Shaping Black Boys: Exploring School Construction of Masculinity and the Impact on Black Male Scholastic Perceptions Toward Academic Achievement and Schooling (PhD). Loyola University Chicago.

Jones, I., \& Gratton, C. (2015). Research methods for sports studies (3 ${ }^{\text {rd }}$ ed.). Routledge.

Miller, M. (2016). The Ethnicity Attainment Gap: Literature Review. The University of Sheffield. https://www.sheffield.ac.uk/polopoly_fs/1.661523!/file/BME_Attainment_Gap_Literature_Review_EXTERNAL___Miriam_Miller.pdf

National Union of Students (NUS), \& Universities UK. (2019). Black, Asian and Minority Ethnic Student Attainment at UK Universities: Case Studies. Universities UK. Retrieved from https://www.universitiesuk.ac.uk/policy-and-analysis/reports/Documents/2019/ bame-student-attainment-uk-universities-case-studies.pdf

National Union of Students (NUS). (2011). Race for equality (pp. 12-55). National Union of Students. https://www.nusconnect.org.uk/resources/race-for-equality-a-report-onthe-experiences-of-black-students-in-further-and-higher-education-2011

Neville, H., Awad, G., Brooks, J., Flores, M., \& Bluemel, J. (2013). Color-blind racial ideology: Theory, training, and measurement implications in psychology. American Psychologist, 68(6), 455-466. https://doi.org/10.1037/a0033282

Pereira, D., Reay, K., Bottell, J., Walker, L., Dzikiti, C., Platt, C., \& Goodrham, C. (2019). University Student Mental Health Survey 2018 (pp. 6-10). The Insight Network and Dig-In. https:// uploads-ssl.webflow.com/561110743bc7e45e78292140/5c7d4b5d314d163fecdc3706_ Mental\%20Health\%20Report\%202018.pdf

Phillips, C. (2011). Institutional Racism and Ethnic Inequalities: An Expanded Multilevel Framework. Journal Of Social Policy, 40(1), 173-192. https://doi.org/10.1017/ s0047279410000565

Richardson, J. (2008). The attainment of ethnic minority students in UK higher education. Studies In Higher Education, 33(1), 33-48. https://doi.org/10.1080/0307507 0701794783

Ross, F., Tatam, J., Hughes, A., Beacock, O., \& McDuff, N. (2018). "The great unspoken shame of UK Higher Education": addressing inequalities of attainment. African Journal Of Business Ethics, 12(1). https://doi.org/10.15249/12-1-172

Sawchuk, S. (2021). A Lesson on Critical Race Theory. Americanbar.org. Retrieved 6 July 2021. https://www.americanbar.org/groups/crsj/publications/human_rights_magazine_ home/civil-rights-reimagining-policing/a-lesson-on-critical-race-theory/

Schacter, H., \& Juvonen, J. (2015). The effects of school-level victimization on self-blame: Evidence for contextualized social cognitions. Developmental Psychology, 51(6), 841847. https://doi.org/10.1037/dev0000016

Senior, N. (2012). Exploring the retention and attainment of black and minority ethnic (BME) students on Social Policy pathways in higher education. The Higher Education Academy. https://s3.eu-west-2.amazonaws.com/assets.creode.advancehe-document-manager/documents/hea/private/exploring_retention_and_attainment_of_bme_students_nicki_senior_1568036743.pdf 
Silverman, S. (2011). Cultural Deficit Perspective. Encyclopedia Of Child Behavior And Development. Springer: Boston, MA.

Sithole, N. (2017). Promoting a positive learning environment: school setting investigation (Masters). University of South Africa.

Sleeter, C., \& Grant, C. (2008). Making Choices For Multicultural Education: Five Approaches To Race, Class And Gender ( $6^{\text {th }}$ ed.). Wiley.

Smit, R. (2012). Towards a clearer understanding of student disadvantage in higher education: problematising deficit thinking. Higher Education Research \& Development, 31(3), 369-380. https://doi.org/10.1080/07294360.2011.634383

Stevenson, J. (2012). Black and minority ethnic student degree retention and attainment. York: The Higher Education Academy. https://s3.eu-west-2.amazonaws.com/assets.creode.advancehe-document-manager/documents/hea/private/bme_summit_final_ report_1568036653.pdf

Stevenson, J., \& Whelan, P. (2013). Synthesis of US literature relating to the retention, progression, completion and attainment of black and minority ethnic (BME) students in HE. Higher Education Academy. https://s3.eu-west-2.amazonaws.com/assets.creode.advancehedocument-manager/documents/hea/private/bme_report_js_0_1568037081.pdf

Tate, S. (2019). Tackling the 'BPOC' Attainment Gap in UK Universities| Shirley Anne Tate | TEDxRoyalCentralSchool [Video]. https://www.youtube.com/watch?v=UPMuuJrfawQ $\& \mathrm{t}=3 \mathrm{~s}$

Thomas, L. (2012). Building student engagement and belonging in Higher Education at a time of change. AdvancedHE. https://www.advance-he.ac.uk/knowledge-hub/buildingstudent-engagement-and-belonging-higher-education-time-change-final-report

Thomas, L., \& Quinn, J. (2007). First generation entry into higher education. Open University Press.

Volk, D., \& Long, S. (2005). Challenging Myths of the Deficit Perspective: Honoring Children's Literacy Resources. YC Young Children, 60(6), 12-19. https://search.proquest. com/docview/197682824/fulltextPDF/B56E24DA3A54524PQ/5?accountid=12834

Weiner, L. (2006). Challenging Deficit Thinking. Educational Leadership: Teaching To Student Strengths, 64(1), 42-45. Retrieved 13 February 2021. http://www.ascd.org/ASCD/pdf/ journals/ed_lead/el200609_weiner.pdf

Yap, J. (2018). The Declining State Of Student Mental Health In Universities And What Can Be Done [Blog]. Retrieved 13 February 2021. https://www.mentalhealth.org.uk/blog/ declining-state-student-mental-health-universities-and-what-can-be-done 